\title{
Summary of the Reconnaissance Investigation of the Diamond Resource Potential and Production Capacity of Côte d'Ivoire
}

\section{Introduction}

This study presents the results of a multiyear effort to monitor the diamond mining activities of Côte d'Ivoire's two main diamond regions, Séguéla and Tortiya. The innovative approach developed for this study integrates archival reports and maps, high-resolution satellite imagery, and terrain modeling to assess the diamond resource potential and production capacity of the Séguéla and Tortiya deposits.

\section{Estimating Diamond Resource Reserves}

A geologic resource assessment was conducted to calculate the remaining diamond reserves for Séguéla and Tortiya using archival geologic data, including gravel grade and thickness recorded by the Ivorian mining company Société pour le Développement Minier (SODEMI). These data were combined with terrain analysis and geomorphological maps in a geological process-driven model. After accounting for previous production, a total of 10,100,000 carats are estimated to be remaining in Séguéla and a total of 1,100,000 carats are estimated to be remaining in Tortiya, based on currently known deposits.

\section{Production Capacity Assessment}

Annual alluvial and primary diamond production was calculated for Séguéla and Tortiya for the years 2006 through 2010 and 2012. Alluvial production in Séguéla was determined through the analysis of high-resolution satellite imagery to catalog the location and size of all active diamond mining pits (fig. 1). Annual production is calculated by multiplying the number of pits per year with grade and gravel thickness data. Primary production from Séguéla's two actively mined kimberlite dikes, Bobi and Diarabana, was determined using high-resolution satellite imagery and digital elevation models to calculate the volume of excavated material. The volume was then multiplied by the grade of the deposits to arrive at the number of carats produced for the years 2006-2012.
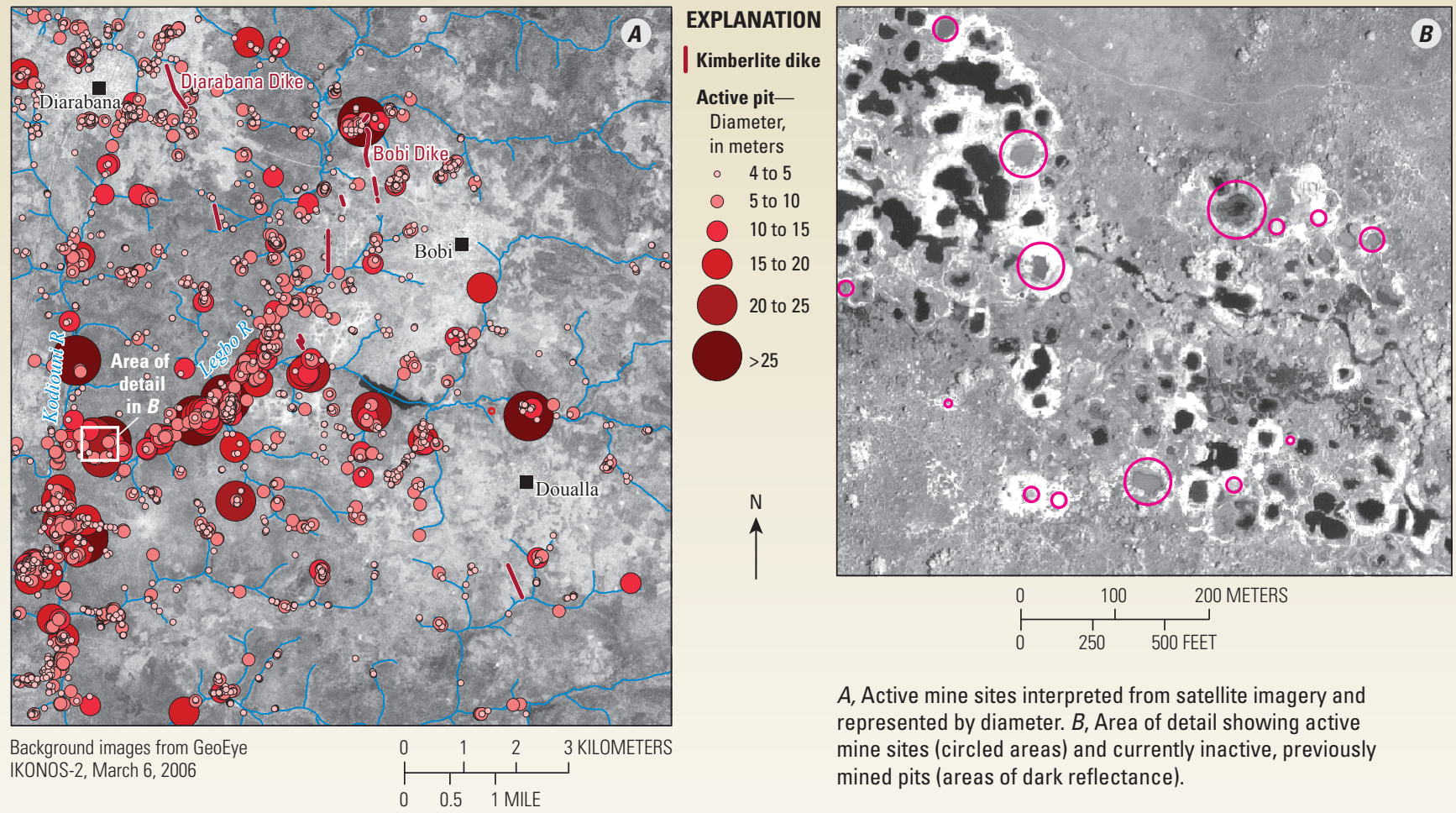

$A$, Active mine sites interpreted from satellite imagery and represented by diameter. $B$, Area of detail showing active mine sites (circled areas) and currently inactive, previously mined pits (areas of dark reflectance).

Figure 1. Example of the use of satellite imagery to locate active pits in Côte d'Ivoire. 
A modified approach was implemented for the Tortiya study area. Data on the number of diggers, the number of days diggers work per year, the volume of material worked per digger per day, and gravel grade were combined to calculate production capacity. The results of the production capacity analysis for Séguéla and Tortiya are presented in table 1.

Figure 2 displays alluvial, primary, and total production values for Séguéla from 2006 to 2012. Analysis was not completed, however, for 2011 due to a lack of available imagery. Figure 3 displays the relation between alluvial and primary production in Séguéla and alluvial production in Tortiya.

The detailed analysis of production in Séguéla resulted in the identification of several notable trends. Total production in Séguéla increased by 75 percent from 2006 to 2009, dropped by 10 percent from 2009 to 2010 , then dropped by 40 percent after 2010 , returning to 2007 production levels. The discovery of the Diarabana Dike in 2009 is one influential factor leading to the peak in total production for that year. Following the discovery of the dike, alluvial production decreased, as more miners chose to exploit the richer primary deposits.

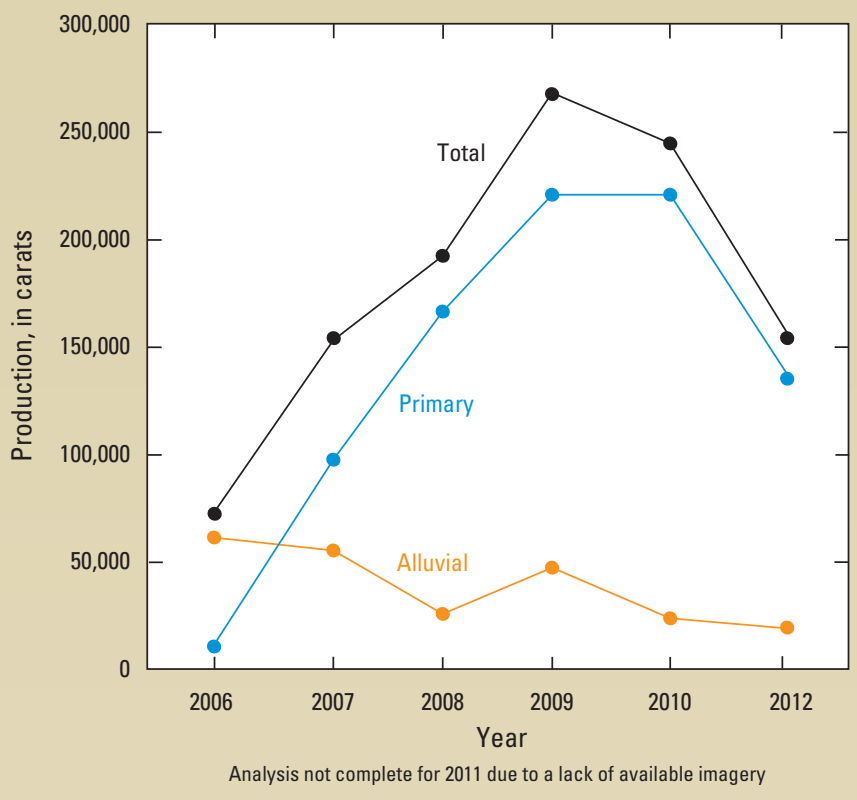

Figure 2. Alluvial production, primary production, and total production for Séguéla from 2006 to 2012.

Table 1. Results of the production capacity analysis for Séguéla and Tortiya.

\begin{tabular}{ccccc}
\hline Year & \multicolumn{2}{c}{$\begin{array}{c}\text { Séguéla production } \\
\text { (carats) }\end{array}$} & $\begin{array}{c}\text { Tortiya } \\
\text { production } \\
\text { (carats)* }\end{array}$ & $\begin{array}{c}\text { Séguéla and Tortiya } \\
\text { production } \\
\text { (carats) }\end{array}$ \\
\cline { 2 - 5 } & \multicolumn{1}{c}{ Alluvial } & \multicolumn{1}{c}{ Primary } & Alluvial & Alluvial and Primary \\
\hline 2006 & $61,704.75$ & $9,656.00$ & $19,687.50$ & $91,048.25$ \\
2007 & $55,572.77$ & $97,752.00$ & $19,687.50$ & $173,012.27$ \\
2008 & $25,957.70$ & $166,604.00$ & $19,687.50$ & $212,249.20$ \\
2009 & $47,514.16$ & $220,937.00$ & $19,687.50$ & $288,138.66$ \\
2010 & $23,925.23$ & $220,937.00$ & $19,687.50$ & $264,549.73$ \\
2012 & $19,100.47$ & $134,601.00$ & $19,687.50$ & $173,388.97$ \\
\hline
\end{tabular}

*Due to constraints on the availability of data, a range of production was calculated for Tortiya. The annual average of this range is presented in this table.

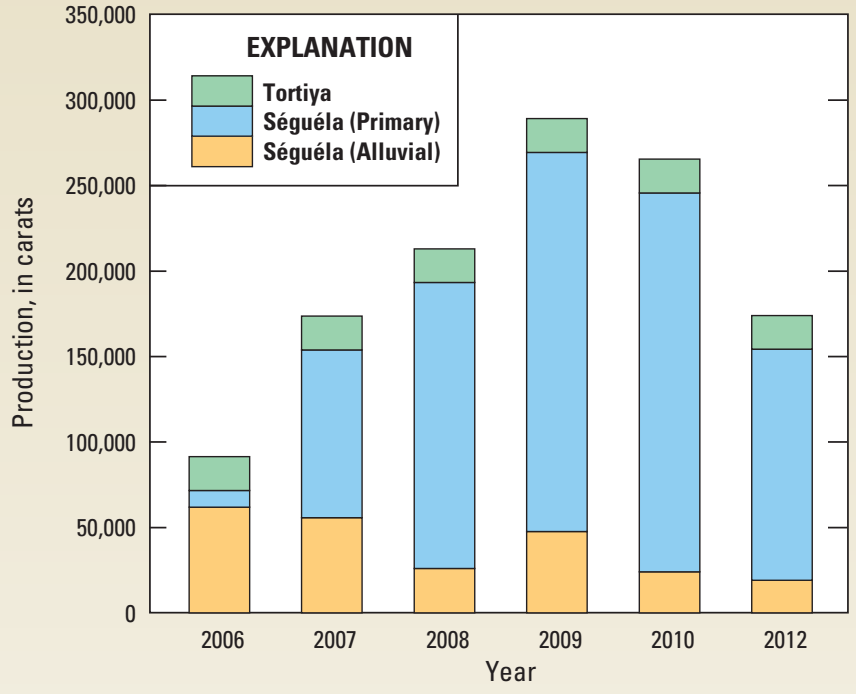

Figure 3. The relation between Séguéla alluvial production, Séguéla primary production, and Tortiya production.

\section{Conclusion}

This study presents a methodology for calculating the resource reserves and production capacity of Séguéla and Tortiya. While this analysis incorporates the best available data, significant data gaps remain. The acquisition of additional geologic and geomorphic data would improve the results of the study, which will be updated should such data become available.

\section{Additional Information}

Peter G. Chirico

12201 Sunrise Valley Drive

National Center, MS 926A

Reston, VA 20192

pchirico@usgs.gov
Katherine C. Malpeli

12201 Sunrise Valley Drive

National Center, MS 926A

Reston, VA 20192

kmalpeli@usgs.gov 